\title{
KOMPOSISI, STRUKTUR, DAN KEANEKARAGAMAN JENIS VEGETASI DI JALUR WISATA AIR TERJUN WIYONO ATAS TAMAN HUTAN RAYA WAN ABDUL RACHMAN PROVINSI LAMPUNG
}

\section{(COMPOSITION, STRUCTURE, AND DIVERSITY OF VEGETATION TYPES IN WATERFALL WIYONO ATAS WAN ABDUL RACHMAN GRAND FOREST PARK)}

\author{
Ardiyansa Dwi Saputra, Indriyanto, dan Duryat \\ Jurusan Kehutanan Fakultas Pertanian Universitas Lampung \\ Jl. Soemantri Brojonegoro No.1 Bandar Lampung, 35145 \\ E-mail : ardiyansa.ds@gmail.com
}

\begin{abstract}
ABSTRAK
Taman Hutan Raya Wan Abdul Rachman memiliki potensi sumberdaya alam yang dapat dijadikan sebagai tujuan wisata alam. Salah satu potensi wisata tersebut adalah Air Terjun Wiyono Atas. Selain air terjun, keanekaragaman tumbuhan yang ditemukan di sekitar air terjun juga memiliki potensi untuk mendukung pariwisata. Penelitian ini bertujuan untuk mengetahui komposisi jenis tumbuhan, struktur vegetasi berdasarkan kerapatan tiap fase pertumbuhan, dan keanekaragaman jenis tumbuhan di jalur wisata tersebut. Penelitian dilakukan pada bulan Mei-Juni 2015. Metode yang digunakan adalah analisis vegetasi dengan garis berpetak sebagai metode sampling. Jumlah petak contoh 44 buah yang terdiri dari jalur kiri dan kanan masing-masing 22 buah, dan jarak antar petak contoh $80 \mathrm{~m}$. Analisis yang digunakan berupa kerapatan, frekuensi, dominansi, indeks nilai penting, indek keanekaragaman Shannon, dan stratifikasi tajuk. Hasil penelitian menunjukkan bahwa komposisi tumbuhan pada jalur wisata ini tersusun atas 28 spesies pada jalur kiri dan 31 spesies pada jalur kanan. Kerapatan vegetasi pada jalur wisata ini tergolong tinggi pada fase semai 11.600 individu/ha, sapihan 1.880 individu/ha, dan kerapatan tergolong rendah pada fase tiang 350 individu/ha, dan pohon 63,64 individu/ha yang ada pada jalur kiri, sedangkan pada jalur kanan memiliki kerapatan tergolong tinggi pada fase semai 10.900 individu/ha, sapihan 1.140 individu/ha, dan kerapatan tergolong rendah pada fase tiang 309,09 individu/ha, dan pohon 86,36 individu/ha. Vegetasi penyusun jalur wisata ini memiliki 5 stratum yang lengkap mulai dari stratum A, B, C, D, dan E. Keanekaragaman pada jalur wisata ini tergolong rendah dengan nilai keanekaragaman di jalur kiri sebesar 1,197 dan jalur kanan dengan nilai sebesar 1,189 .
\end{abstract}

Kata kunci : komposisi, struktur, keanekaragaman, Taman Hutan Raya

\section{ABSTRACT}

Wan Abdul Rachman Grand Forest Park has a potential of natural resources that can be used as natural attractions. One of the tourism potential is The Waterfall of Wiyono Atas. In addition, plant diversity found around the waterfall also has a potential to support the tourism. The aims of the research was to figure out the composition of plant species, structure of vegetation based on the density of each growth phase, and diversity of plant along the tourism track. The research was conducted in May-June 2015. Vegetation analysis with aterraced plot was employed as sampling method, that was consisting 44 plots which were 22 plots for left track and 22 plots for right track, and the distance between plots was $80 \mathrm{~m}$. The analysis of density, frequency, dominance, 
important value index, Shannon diversity index, and canopy stratification were used as data analysis. The results showed that the plant composition along the tourism track was made up of 28 species in the left track and 31 species in the right track. The vegetation density of tourism track was classified as high on seedling phase for 11,600 individu/ha, sapling phase 1,880 individu/ha, and it was classified low density on pole phase for 350 individu/ha, and tree phase for 63.64 individu/ha on the left track, while on the right track, vegetatation density was classified as high on seedling phase for 10,900 individu/ha, sapling phase for 1,140 individu/ha, and classified low density on pole phase for 309.09 individu/ha, and tree phase for 86.36 individu/ha. The vegetation former, consist of 5 stratum, ranging from stratum $A, B, C, D$, and $E$. The diversity in the tourism track was classified as low, with the value of diversity in the left track of 1.197 and the right track of 1.189.

Keywords: composition, diversity, Grand Forest Park, structures

\title{
PENDAHULUAN
}

\section{Latar Belakang}

Taman Hutan Raya Wan Abdul Rachman (Tahura WAR) secara geografis terletak di antara $105^{\circ} 02$ ' 42,01" dan $105^{\circ} 13^{\prime} 42,09$ 'BT, di antara $05^{\circ} 23^{\prime} 47,03$ " dan $05^{0} 30^{\prime} 34,86^{\prime \prime} \mathrm{LS}$, serta memiliki luas wilayah $22.249,31$ ha. Taman hutan raya memiliki potensi sumber daya alam yang dapat dijadikan sebagai tujuan wisata alam. Lokasi wisata alam tersebut terletak di Sub/Seksi/Resort Gedung Tataan yaitu Air Terjun Wiyono (Unit Pelaksana Teknis Daerah Taman Hutan Raya Wan Abdul Rachman, 2009).

Air Terjun Wiyono Atas berpotensi untuk tujuan wisata, tetapi tidak hanya air terjunnya saja yang memiliki nilai keindahan. Vegetasi tumbuhan-tumbuhan yang beraneka ragam jenis yang berada di sekitar Air Terjun Wiyono Atas, juga dapat menjadi pendukung daya tarik wisata, terutama di sepanjang jalan menuju air terjun Wiyono Atas. Pada jalur wisata tersebut perlu dilakukan penghitungan jumlah jenis tumbuhan untuk mengetahui, keanekaragaman jenis tumbuhan yang dapat dijadikan sebagai atraksi wisata yang baik.

Sampai saat ini belum ada data hasil kajian tentang komposisi, struktur, dan keanekaragaman jenis vegetasi di sepanjang jalur wisata Air Terjun Wiyono Atas, yang dapat dijadikan sebagai pendukung daya tarik wisata untuk para wisatawan yang ingin mengunjungi air terjun tersebut. Dalam rangka mendukung objek wisata yang telah lebih dulu dikenal, perlu dilakukan kajian tentang komposisi, struktur dan keaneka ragaman jenis vegetasi, struktur vegetasi berdasarkan tiap fase pertumbuhan dan keaneka ragaman jenis tumbuhan yang gunanya untuk mengetahui tingkat keragaman jenis tumbuhan yang ada di sepanjang jalan menuju Air Terjun Wiyono Atas untuk dijadikan sebagai penambah daya tarik wisata.

\section{METODE PENELITIAN}

\section{Waktu dan Lokasi Penelitian}

Penelitian ini telah dilakukan pada Mei-Juni 2015 yang bertempat di Air Terjun Wiyono Sub/Seksi/Resort Gedung Tataan, Tahura Wan Abdul Rachman Provinsi Lampung.

\begin{abstract}
Alat dan Bahan
Alat-alat yang digunakan pada penelitian ini terdiri atas global positioning system (GPS) Garmin 72, roll meter kain ukuran $100 \mathrm{~m}$, pita ukur dengan ketelitian 0,01 mm, christen hypsometer, tali rafia gulungan besar, peta lokasi penelitian, dan kamera digital canon d600 dengan resolusi 24.0 megapixel,dan pembesaran 5 kali. Bahan yang digunakan adalah tegakan hutan di jalur wisata Air Terjun Wiyono Atas.
\end{abstract}




\section{Jenis Data}

\section{Data Primer}

Data primer yang dihimpun meliputi: jenis tumbuhan, tinggi tumbuhan, jumlah individu setiap jenis tumbuhan, diameter batang pohon dan perdu, fase pertumbuhan pohon, keanekaragaman jenis tumbuhan yang digunakan untuk mengetahui keragaman jenis tumbuhan yang ada di jalur wisata Air Terjun Wiyono Atas sebagai daya tarik wisata, dan gambar fisiognomi pada setiap segmen pengamatan.

\section{Data Sekunder}

Data sekunder yang dibutuhkan pada penelitian ini meliputi: gambaran umum tentang status kawasan yang terdiri dari potensi objek wisata, aksesibilitas, peta lokasi, iklim, jenis tanah, topografi, dan kondisi sosial ekonomi masyarakat.

\section{Metode Pengumpulan Data}

\section{Data Primer}

Pengumpulan data primer meliputi data komposisi jenis dan struktur vegetasi dilakukan dengan metode garis berpetak dengan jumlah plot kanan sebanyak 22 plot dan plot kiri sebanyak 22 plot, sehingga total keseluruhan plotnya adalah 44 plot dengan jarak antar plot $80 \mathrm{~m}$. Metode garis berpetak ini dipilih dengan alasan pelaksanaan lebih cepat (sederhana) dan kesalahan yang timbul paling kecil dibandingkan metode yang lain (Simon, 1996). Penggunaan metode garis berpetak ini akan menghasilkan data berupa jenis tumbuhan, tinggi tumbuhan, jumlah individu setiap jenis tumbuhan, diameter batang pohon dan perdu, fase pertumbuhan pohon, dan keanekaragaman tumbuhan. Tahapan kegiatan-kegiatan pada penelitian ini adalah sebagai berikut.

1) Tahapan pertama adalah membuat jalur pengamatan. Plot pertama diletakkan secara purposive yaitu $10 \mathrm{~m}$ dari Pos Loket Administrasi untuk masuk ke Kawasan Gunung Betung Tahura Wan Abdul Rachman. Titik ini diambil karena untuk menghindari efek pinggir kawasan hutan yang berbatasan dengan kebun masyarakat. Jarak antar plot pada jalur pengamatan adalah $80 \mathrm{~m}$. Desain petak-petak contoh di lapangan disajikan pada

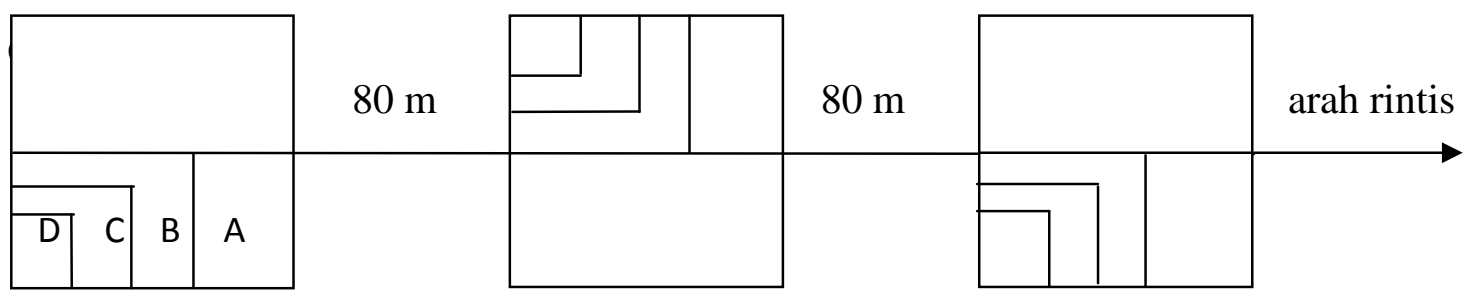

Gambar 1. Desain petak-petak contoh di lapangan dengan metode garis berpetak.

Keterangan :

Petak $\mathrm{A}=$ Petak berukuran $20 \mathrm{~m} \times 20 \mathrm{~m}$ untuk pengamatan fase pohon.

Petak B = Petak berukuran $10 \mathrm{~m} \times 10 \mathrm{~m}$ untuk pengamatan fase tiang dan perdu.

Petak $\mathrm{C}=$ Petak berukuran $5 \mathrm{~m} \times 5 \mathrm{~m}$ untuk pengamatan fase pancang.

Petak D = Petak berukuran $2 \mathrm{~m}$ x $2 \mathrm{~m}$ untuk pengamatan fase semai dan semak.

2) Tahapan kedua adalah inventarisasi spesies tumbuhan. Inventarisasi spesies tumbuhan dilakukan untuk tiap fase pertumbuhan yang meliputi: pohon, tiang, pancang, semai, golongan perdu, dan semak.

3) Tahap ketiga adalah pendataan dimensi pohon. Dimensi pohon meliputi diameter, tinggi, dan luas bidang dasar (LBD) pendataan dilakukan untuk fase pohon tiang, pancang dan golongan perdu. Pada fase semai dan semak pendataan identitas hanya meliputi nama spesies, dan jumlah individu untuk tiap plot. 
4) Tahap keempat adalah mengambilan gambar (foto) fisiognomi vegetasi pada setiap segmen pengamatan.

5) Tahap kelima adalah tabulasi data.

6) Tahap keenam adalah analisis data.

\section{Data Sekunder}

Pengumpulan data sekunder dilakukan studi pustaka dan pengumpulan informasi dari instansi-instansi terkait. Kegiatan ini dilakukan untuk mencari, mengumpulkan, dan menganalisis data penunjang. Data sekunder yang digunakan antara lain meliputi: data dari UPTD Tahura Wan Abdul Rachman berupa gambaran umum tentang status kawasan mencangkup dari potensi wisata Air Terjun Wiyono Atas, aksesbilitas, peta lokasi, jenis tanah, iklim, dan topografi. Data sekunder yang bersumber dari Kantor Kelurahan Desa Wiyono berupa kondisi sosial ekonomi masyarakat.

\section{Analisis Data}

Analisis data yang digunakan pada penelitian ini berupa : kerapatan, frekuensi, dominansi, indeks nilai penting, stratifikasi tajuk, penilaian estetika dan keanekaragaman spesies (H'). Nilai H' dikategorikan sebagai berikut (Odum,1993).

1. $\mathrm{H}^{\prime}<2$ : keanekaragaman rendah

2. H' 2--3 : keanekaragaman sedang

3. $\mathrm{H}^{\prime}>3$ : keanekaragaman tinggi

\section{HASIL DAN PEMBAHASAN}

\section{Hasil Penelitian}

\section{Jenis-jenis tumbuhan}

Jenis-jenis tumbuhan yang terdapat pada jalur kiri dan jalur kanan pada jalur wisata Air Terjun Wiyono Atas Taman Hutan Raya Wan Abdul Rachman disajikan pada Tabel 1 berikut. 
Tabel 1. Hasil analisis vegetasi tumbuhan pada jalur kiri dan jalur kanan di jalur wisata Air Terjun Wiyono Atas Taman Hutan Raya Wan Abdul Rachman Provinsi Lampung.

\begin{tabular}{|c|c|c|c|c|c|}
\hline \multirow{3}{*}{ No. } & \multicolumn{2}{|c|}{ Jalur kiri } & \multicolumn{3}{|c|}{ Jalur kanan } \\
\hline & \multicolumn{2}{|c|}{ Jenis tumbuhan } & \multirow{2}{*}{ No. } & \multicolumn{2}{|c|}{ Jenis tumbuhan } \\
\hline & Nama Lokal & Nama Ilmiah & & Nama Lokal & Nama Ilmiah \\
\hline 1. & Alpukat & Persea americana & 1. & Alpukat & Persea americana \\
\hline 2. & Aren & Arenga pinnata & 2. & Aren & Arenga pinnata \\
\hline 3. & Bayur & Pterospermum javanicum & 3. & Balik angin & Ficus fulva \\
\hline 4. & Bendo & Artocarpus elasticus & 4. & Bayur & Pterospermum javanicum \\
\hline 5. & Binong & Tetrameles nudiflora & 5. & Bendo & Artocarpus elasticus \\
\hline 6. & Cempaka & Michelia champaca & 6. & Binong & Tetrameles nudiflora \\
\hline 7. & Cengkeh & Eugenia aromatica & 7. & Cempaka & Michelia champaca \\
\hline 8. & Dadap & Erythrina variegata & 8. & Cempedak & Artocarpus integra \\
\hline 9. & Durian & Durio zibethinus & 9. & Cengkeh & Eugenia aromatica \\
\hline 10. & Gamal & Gliricidia maculata & 10. & Durian & Durio zibethinus \\
\hline 11. & Harendong bulu & Clidemia hirta & 11. & Gamal & Gliricidia maculata \\
\hline 12. & Jelatong & Laportea sinuata & 12. & Harendong bulu & Clidemia hirta \\
\hline 13. & Kakao & Theobroma cacao & 13. & Kakao & Theobroma cacao \\
\hline 14. & $\begin{array}{l}\text { Kaliandra bunga } \\
\text { putih }\end{array}$ & Calliandra tetragona & 14. & $\begin{array}{l}\text { Kaliandra bunga } \\
\text { merah }\end{array}$ & Calliandra calothyrsus \\
\hline 15. & Karet & Hevea brasiliensis & 15 . & Karet & Hevea brasiliensis \\
\hline 16. & Kemiri & Aleurites moluccana & 16. & Kemiri & Aleurites moluccana \\
\hline 17. & Kopi & Coffea arabica & 17. & Kopi & Coffea arabica \\
\hline 18. & Luwingan & Ficus hispida & 18. & Luwingan & Ficus hispida \\
\hline 19. & Medang lana & Dehaasia cuneata & 19. & $\begin{array}{l}\text { Mahoni daun } \\
\text { kecil }\end{array}$ & Swietenia mahagoni \\
\hline 20. & Mindi & Melia azedarach & 20. & Mangga & Mangifera indica \\
\hline 21. & Nangka & Artocarpus heterophylla & 21. & Medang lana & Dehaasia cuneata \\
\hline 22. & Orok-orok & Crotalaria striata & 22. & Mindi & Melia azedarach \\
\hline 23. & Pala & Myristica fragrans & 23. & Nangka & Artocarpus heterophylla \\
\hline 24. & Petai & Parkia speciosa & 24. & Orok-orok & Crotalaria striata \\
\hline 25. & Randu & Ceiba pentandra & 25 . & Pala & Myristica fragrans \\
\hline 26. & Sonokeling & Dalbergia latifolia & 26. & Petai & Parkia speciosa \\
\hline 27. & Suren & Toona sureni & 27. & Petai cina & Leucaena glauca \\
\hline \multirow[t]{4}{*}{28.} & Waru & Hibiscus tiliaceus & 28. & Pulai & Alstonia scholaris \\
\hline & & & 29. & Pulutan & Urena lobata \\
\hline & & & 30. & Randu & Ceiba pentandra \\
\hline & & & 31. & Sonokeling & Dalbergia latifolia \\
\hline
\end{tabular}




\section{Komposisi Jenis dan Stratifikasi Tajuk}

\section{Jalur kiri}

Komposisi jenis dan stratifikasi tajuk pada jalur kiri di jalur wisata ini disajikan pada Tabel 2 berikut.

Tabel 2. Komposisi jenis tumbuhan penyusun vegetasi jalur kiri di Jalur Wisata Air Terjun Wiyono Atas Taman Hutan Wan Abdul Rachman Provinsi Lampung.

\begin{tabular}{|c|c|c|c|}
\hline $\begin{array}{c}\text { No. Urut } \\
\text { Kompo- } \\
\text { sisi }\end{array}$ & $\begin{array}{c}\text { Jumlah } \\
\text { Jenis } \\
\text { (buah) }\end{array}$ & Jenis-jenis tumbuhan & Jumlah strata \\
\hline \multirow[t]{2}{*}{1.} & 1 & Kakao & 2 strata: $\mathrm{C}$ dan $\mathrm{D}$ \\
\hline & & Kakao & 2 strata : C dan D \\
\hline \multirow[t]{2}{*}{2} & 2 & Durian dan kakao & 2 strata: $C$ dan $D$ \\
\hline & & Kakao dan mindi & 3 strata : B, C, dan D \\
\hline \multirow[t]{3}{*}{3.} & 3 & Gamal,harendong bulu, dan kakao & 2 strata : C dan D \\
\hline & & Cempaka, harendong bulu, dan kakao & 3 strata: C, D dan E \\
\hline & & Bendo, jelatong, dan medang lana & 4 strata : A, C, D dan E \\
\hline 4. & 4 & Alpukat, karet, kopi, dan sonokeling & 2 strata : C dan D \\
\hline \multirow[t]{6}{*}{5 . } & 5 & Bayur, cengkeh, gamal, kakao, dan karet & 2 strata: $C$ dan $D$ \\
\hline & & $\begin{array}{l}\text { Gamal, harendong bulu, kakao, kaliandra bunga } \\
\text { putih, dan nangka }\end{array}$ & 3 strata: $\mathrm{C}, \mathrm{D}$ dan $\mathrm{E}$ \\
\hline & & Aren, durian, harendong bulu, kakao, dan karet & 3 strata: $\mathrm{C}, \mathrm{D}$ dan $\mathrm{E}$ \\
\hline & & Cengkeh, harendong bulu, kakao, karet,dan kopi & 3 strata : C, D dan E \\
\hline & & Binong, karet, kopi, luwingan, dan orok-orok & 3 strata: $\mathrm{C}, \mathrm{D}$ dan $\mathrm{E}$ \\
\hline & & Aren, harendong bulu, karet, medang lana, dan suren & 4 strata : B, C, D dan E \\
\hline \multirow[t]{6}{*}{6.} & 6 & Alpukat, bayur, cengkeh, durian, kakao, dan pala & 2 strata: $\mathrm{C}$ dan $\mathrm{E}$ \\
\hline & & $\begin{array}{l}\text { Cengkeh, durian, harendong bulu, kakao, karet, dan } \\
\text { petai }\end{array}$ & 3 strata: $\mathrm{C}, \mathrm{D}$ dan $\mathrm{E}$ \\
\hline & & $\begin{array}{l}\text { Durian, kakao, kaliandra bunga putih, karet, pala, dan } \\
\text { petai }\end{array}$ & 3 strata: $\mathrm{C}, \mathrm{D}$ dan $\mathrm{E}$ \\
\hline & & Durian, kakao, karet, nangka, pala, dan petai & 3 strata: C, D dan E \\
\hline & & Alpukat, bayur, cengkeh, durian, gamal, dan kakao & 3 strata: $\mathrm{C}, \mathrm{D}$ dan $\mathrm{E}$ \\
\hline & & $\begin{array}{l}\text { Binong, dadap, gamal, harendong bulu, kemiri, dan } \\
\text { kopi }\end{array}$ & 4 strata : B, C, D dan E \\
\hline \multirow[t]{2}{*}{7.} & 7 & $\begin{array}{l}\text { Gamal, harendong bulu, kemiri, kopi, nangka, randu, } \\
\text { dan waru }\end{array}$ & 3 strata: C, D dan E \\
\hline & & $\begin{array}{l}\text { Alpukat, cempaka, harendong bulu, karet, kopi, } \\
\text { nangka, dan randu }\end{array}$ & 3 strata : C, D dan $\mathrm{E}$ \\
\hline
\end{tabular}




\section{Jalur kanan}

Komposisi jenis dan stratifikasi tajuk pada jalur kanan di jalur wisata ini disajikan pada Tabel 3 berikut.

Tabel 3. Komposisi jenis penyusun vegetasi di jalur kanan jalur wisata Air Terjun Wiyono Atas Taman Hutan Wan Abdul Rachman Provinsi Lampung.

\begin{tabular}{|c|c|c|c|}
\hline $\begin{array}{c}\text { No. } \\
\text { Urut } \\
\text { kompo- } \\
\text { Sisi }\end{array}$ & $\begin{array}{l}\text { Jumlah } \\
\text { Jenis } \\
\text { (buah) }\end{array}$ & Jenis-jenis tumbuhan & Jumlah strata \\
\hline 1. & 1 & Harendong bulu & 1 strata : $\mathrm{E}$ \\
\hline \multirow[t]{3}{*}{2.} & 3 & Karet, kopi, dan sonokeling & 2 strata: C dan D \\
\hline & & Harendong bulu, kakao, dan petai & 3 strata: $C, D$, dan $E$ \\
\hline & & Kakao, karet, dan mindi & 3 strata: C, D, dan E \\
\hline \multirow[t]{7}{*}{3.} & 4 & Cempaka, cengkeh, harendong bulu, dan karet & 2 strata: $\mathrm{C}$ dan $\mathrm{E}$ \\
\hline & & Cempaka, kakao, kaliandra bunga merah, dan mangga & 3 strata: $\mathrm{C}, \mathrm{D}$, dan $\mathrm{E}$ \\
\hline & & Cempaka, harendong bulu, kakao, dan kemiri & 3 strata: C, D, dan E \\
\hline & & Binong, cengkeh, karet, dan kopi & 3 strata : B, C dan D \\
\hline & & Balik angin, bendo, gamal, dan harendong bulu & 3 strata: C, D dan E \\
\hline & & Aren, harendong bulu, medang lana, dan nangka & 3 strata: A, C dan D \\
\hline & & Balik angin, bendo, harendong bulu, dan luwingan & 3 strata: $A, C$ dan $E$ \\
\hline 4. & 5 & Alpukat, durian, kakao, karet, dan petai & 3 strata: C, D dan E \\
\hline \multirow[t]{4}{*}{5.} & 6 & Cempaka, durian, kakao, karet, petai, dan petai cina & 2 strata: $C$ dan $D$ \\
\hline & & $\begin{array}{l}\text { Cempaka, harendong bulu, kakao, karet, kemiri, dan } \\
\text { pulutan }\end{array}$ & 2 strata: $\mathrm{C}$ dan $\mathrm{E}$ \\
\hline & & Cempaka, durian, kakao, karet, mangga, dan petai & 3 strata : C, D dan E \\
\hline & & $\begin{array}{l}\text { Alpukat, gamal, harendong bulu, kakao, kopi, dan } \\
\text { nangka }\end{array}$ & 3 strata: C, D dan E \\
\hline \multirow[t]{6}{*}{6.} & 7 & $\begin{array}{l}\text { Cengkeh, harendong bulu, kakao, mangga, orok-orok, } \\
\text { petai, dan randu }\end{array}$ & 3 strata: C, D dan E \\
\hline & & $\begin{array}{l}\text { Alpukat, cengkeh, durian, harendong bulu, kakao, } \\
\text { karet, dan nangka }\end{array}$ & 3 strata: C, D dan E \\
\hline & & $\begin{array}{l}\text { Harendong bulu, kakao, kaliandra bunga merah, karet, } \\
\text { mahoni, pala, dan petai }\end{array}$ & 3 strata: C, D dan E \\
\hline & & $\begin{array}{l}\text { Alpukat, cempedak, kakao, karet, kopi, mahoni, dan } \\
\text { nangka }\end{array}$ & 3 strata : C, D dan E \\
\hline & & $\begin{array}{l}\text { Cempaka, harendong bulu, kakao, karet, kopi, pulai, } \\
\text { dan randu }\end{array}$ & 3 strata: C, D dan E \\
\hline & & $\begin{array}{l}\text { Bayur, cempaka, durian, harendong bulu, kakao, petai, } \\
\text { dan pulutan }\end{array}$ & 4 strata : B, C, D dan E \\
\hline
\end{tabular}

\section{Struktur Vegetasi berdasarkan Kerapatan tiap Fase Pertumbuhan}

Perbandingan kerapatan pada semua fase pertumbuhan pada jalur kiri dan jalur kanan di jalur wisata Air Terjun Wiyono Atas selengkapnya disajikan pada Gambar 2 berikut. 


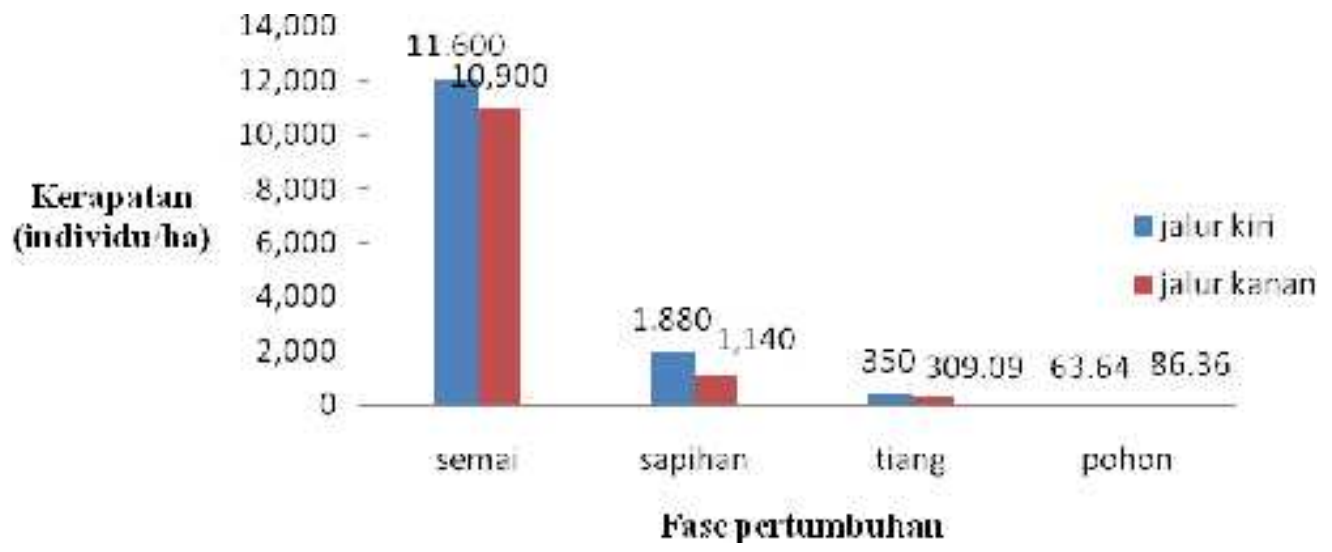

Gambar 2. Histogram struktur vegetasi berdasarkan kerapatan tiap fase pertumbuhan pada jalur kiri dan kanan di jalur wisata Air Terjun Wiyono Atas.

Gambar di atas membentuk kurva $\mathbf{J}$ terbalik yang berarti menunjukkan bahwa regenerasi di wilayah penelitian yaitu di jalur kiri dan kanan pada jalur wisata Air Terjun Wiyono Atas ini cukup baik ditandai dengan semakin rendah fase pertumbuhan, maka semakin besar populasinya regenerasinya dianggap cukup baik.

\section{Keanekaragaman Spesies (H')}

Indek keanekaragaman spesies (H') pada komunitas tumbuhan pada jalur kiri dan jalur kanan di jalur wisata Air Terjun Wiyono Atas Taman Hutan Raya Wan Abdul Rachman adalah tergolong rendah dengan nilai $H^{\prime}$ pada jalur kiri 1,197, memiliki kerapatan total 13.893,38 individu/ha, dan memiliki jumlah jenis tumbuhan 28 buah. Pada jalur kanan memiliki nilai $H^{\prime}$ yang tergolong rendah dengan nilai 1,189 , kerapatan total $12.435,47$ individu/ha, dan memiliki jumlah jenis tumbuhan 31 buah.

\section{Pembahasan}

\section{Komposisi Jenis dan Stratifikasi Tajuk}

Pada jalur kiri di jalur wisata Air Terjun Wiyono Atas ditemukan 28 jenis tumbuhan dengan kerapatan sebesar 13.893,38 individu/ha. Jenis tumbuhan yang paling besar kerapatannya adalah harendong bulu (Clidemia hirta) sebesar 4.000 individu/ha, sedangkan jenis tumbuhan yang paling kecil kerapatannya adalah bendo (Artocarpus elasticus) sebesar 1,14 individu/ha. Sedangkan Pada jalur kanan di jalur wisata Air Terjun Wiyono Atas ditemukan 31 jenis tumbuhan dengan kerapatan sebesar 12.435,47 individu/ha. Jenis tumbuhan yang paling besar kerapatannya adalah harendong bulu sebesar 5.000 individu/ha, sedangkan jenis tumbuhan yang paling kecil kerapatannya pulai (Alstonia scholaris) sebesar 1,14 individu/ha. Terdapat juga perbedaan jenis-jenis tumbuhan yang ada pada jalur kiri dan jalur kanan di jalur wisata Air Terjun ini yang terjadi karena adanya perbedaan keadaan topografi. Topografi pada jalur kiri memiliki topografi yang lebih rendah dibandingkan dengan topografi pada jalur kanan, sehingga menyebabkan adanya perbedaan jenis tumbuhan yang dapat tumbuh pada jalur kiri dan jalur kanan.

Pada jalur wisata ini diketahui bahwa harendong bulu memiliki kerapatan tertinggi. Hal ini diduga pada jalur wisata ini lahannya telah terbuka karena banyaknya ditemukan harendong bulu. Lokasi jalur wisata Air Terjun Wiyono Atas ini telah digunakan sebagai lahan hutan campuran jenis tanaman perkebunan dan tanaman kayu hutan yang dikelola oleh masyarakat, sehingga memiliki cukup ruang bagi tumbuhan harendong bulu ini untuk tumbuh dan berkembang karena memperoleh cahaya matahari yang cukup. 
Harendong bulu merupakan belukar yang sangat invasif, dan mengisolasi burung yang hidup di hutan-hutan tropis tua. Spesies belukar ini menginvasi bukaan hutan, terutama tempat yang tanahnya telah mengalami gangguan (Meijaard dkk., 2006). Menurut Dwidjoseputro (1994) perdu dan rumput hanya dapat tumbuh di pinggir hutan di mana sinar matahari dapat mencapai tanah. Hal ini disebabkan sinar matahari terhalang oleh atap dedaunan pohon-pohon yang tinggi, sehingga tidak dapat mencapai tanah yang menyebabkan tidak adanya tumbuh rumput dan semak-semak di tanah. Menurut Susanti dkk. (2013) harendong bulu memiliki kemampuan untuk tumbuh pada daerah yang terbuka, sedikit naungan, berbunga sepanjang tahun, memproduksi buah yang melimpah, dan tidak mudah terbakar. Menurut Harada dkk. (2006) harendong bulu adalah sejenis perdu yang tingginya sekitar $0,8 \mathrm{~m}-2 \mathrm{~m}$, daunnya biasa digunakan sebagai pembersih luka, habitat tumbuhan ini biasanya ditemukan di padang belukar, hutan campuran, dan kebun.

Berdasarkan INP-nya, jenis tumbuhan yang memiliki nilai penting tertinggi adalah kakao (Theobroma cacao) dengan INP sebesar 66,54\%, sedangkan jenis tumbuhan paling tidak dominan adalah mindi (Melia azedarach) dengan INP sebesar 1,22\%. Sedangkan di jalur kanan terdapat jenis tumbuhan yang paling dominan adalah kakao dengan INP sebesar $72,3 \%$, sedangkan jenis paling kodominan adalah orok-orok (Crotalaria striata), petai cina (Leucaena glauca), dan pulutan (Urena lobata) dengan INP sebesar 0,91\%. Pada jalur wisata ini diketahui bahwa kakao memiliki INP tertinggi. Hal ini diduga jalur wisata ini telah difungsikan sebagai lahan perkebunan, karena jenis tanamannya adalah tanaman kakao yang merupakan komoditi perkebunan.

Coklat merupakan jenis tanaman perkebunan yang disukai petani karena mempunyai keunggulan yaitu frekuensi panen setiap minggu (Saipurrozi, 2010). Tanaman kakao merupakan salah satu tanaman perkebunan yang dikembangluaskan dalam rangka peningkatan sumber devisa negara dari sektor nonmigas. Tanaman kakao tersebut merupakan salah satu anggota genus Theobrama dari familia Sterculaieeae yang banyak dibudidayakan (Oktora, 2013).

Vegetasi di jalur kiri dan jalur kanan pada jalur wisata ini terdiri dari stratifikasi tajuk yang memiliki strata lengkap yaitu A, B, C, D, dan E, strata yang paling besar ditemukan adalah strata $\mathrm{C}, \mathrm{D}$, dan $\mathrm{E}$ dan yang paling kecil ditemukan di jalur wisata tersebut adalah strata A dan B. Keadaaan tersebut secara ekologi tidak natural. Diduga lahan ini sudah di eksploitasi karena banyaknya strata C, D, dan E, dan tidak baik secara alami.

Stratifikasi tajuk pada lahan hutan yang telah ekploitasi menjadi agroforestri terdapat 3 stratum yaitu stratum $\mathrm{C}$ yang terdiri dari pohon-pohon yang tingginya 4-20 m, tajuknya kontinyu, pohon-pohon dalam stratum ini rendah, kecil dan banyak cabang, yang biasanya ditempati oleh jenis tanaman kemiri, kelapa, cengkeh, dan pinang. Pada stratum yaitu lapisan perdu dan semak yang memiliki tinggi $1-4 \mathrm{~m}$, biasanya ditempati oleh jenis tanaman kopi, dan stratum E lapisan tumbuhan penutup tanah (ground cover) yang memiliki tinggi $0-1 \mathrm{~m}$, dan biasanya ditempati oleh jenis tanaman katela rambat dan keladi (Satyowati dkk., 2008).

\section{Struktur Vegetasi Berdasarkan Kerapatan tiap Fase Pertumbuhan}

Pada jalur kiri di jalur wisata ini memiliki struktur vegetasi berdasarkan kerapatan yang berbeda-beda pada setiap fase pertumbuhannya. Berdasarkan perbandingan kerapatan pada setiap fase pertumbuhan diketahui bahwa kerapatan tertinggi ditempati oleh fase semai yang memiliki jumlah spesies terbanyak yaitu 11.600 individu/ha, kemudian fase sapihan dengan jumlah spesies sebanyak 1.880 individu/ha, diikuti oleh fase tiang dengan jumlah spesies sebanyak 350 individu/ha, dan jumlah terkecil yaitu pada fase pohon 63,64 individu/ha. Sedangkan pada jalur kanan di jalur wisata ini memiliki perbandingan kerapatan pada setiap fase pertumbuhan tumbuhan diketahui bahwa kerapatan tertinggi ditempati oleh fase semai yang memiliki jumlah spesies terbanyak yaitu 10.900 individu/ha, kemudian fase sapihan 
dengan jumlah spesies sebanyak 1.140 individu/ha, diikuti oleh fase tiang dengan jumlah spesies sebanyak 309,09 individu/ha, dan jumlah terkecil yaitu pada fase pohon 86,36 individu/ha.

Berdasarkan data kerapatan tiap fase pertumbuhan di atas diduga pada jalur kanan dan jalur kiri di jalur wisata Air Tejun Wiyono Atas memiliki regenerasi yang cukup baik ditandai dengan semakin rendah fase pertumbuhan, maka semakin besar populasinya. Kondisi tersebut secara ekologi menunjukkan bahwa regenerasi yang terjadi di wilayah tersebut tergolong baik.

Penelitian yang dilakukan oleh Simorangkir dkk. (2009) adalah bahwa di Kawasan Hutan Batang Toru, Sumatera Utara menerangkan sebaran diameter pohon yang sangat bervariasi. Komposisi vegetasi di hutan Batang Toru terdiri dari campuran seluruh kelas diameter dan didominansi oleh pohon berdiameter kecil. Banyaknya tegakan yang memiliki diameter kecil dapat menjamin regenerasi tegakan di Kawasan Hutan Batang Toru di masa mendatang.

Penelitian yang dilakukan oleh Hidayat (2015) adalah bahwa di Hutan Lindung Tanjung Tiga Muara Enim Sumatera Selatan, berdasarkan kelas diameter batang, struktur tegakan di kawasan hutan ini membentuk kurva huruf L atau J terbalik, yang merupakan suatu bentuk umum yang terjadi di hutan hujan tropis. Menurut Suwardi (2013) ketersediaan tegakan pada hutan yang bertipe normal akan membentuk kurva $\mathbf{J}$ terbalik sangat tinggi, sehingga dapat menjamin keberlangsungan tegakan di masa mendatang. Menurut Dendang dkk. (2015) kurva berbentuk huruf $\mathbf{J}$ terbalik menunjukkan, bahwa kondisi hutan berada dalam kondisi normal/seimbang, dimana jumlah individu pada tingkat semai>pancang>tiang>pohon, sehingga proses regenerasi dapat berlangsung karena tersedia permudaan dalam jumlah yang mencukupi. Menurut Widiyanti dkk. (2014) struktur horizontal vegetasi hutan yang membentuk kurva $\mathbf{J}$ terbalik akan menunjukan proses suksesi sekunder yang berjalan baik sejalan dengan pertambahan waktu. Menurut Mirmanto (2014) grafik sebaran kelas diameter batang berbentuk kurva $\mathbf{J}$ terbalik yang mana pada kurva ini menerangkan bahwa, semakin kecil fase pertumbuhan maka jumlah individunya akan semakin besar.

Keberadaan anakan spesies pohon dalam hutan akan mencerminkan kemampuan hutan untuk beregenerasi, sedangkan banyaknya spesies pohon akan mencerminkan potensi plasma nutfah dalam kawasan hutan. Berjalan atau tidaknya proses regenerasi tegakan hutan dicerminkan oleh kondisi anakan pohon yang ada dalam kawasan hutan (Indriyanto, 2008).

\section{Keanekaragaman}

Nilai indeks keanekaragaman pada komunitas tumbuhan pada jalur kiri di jalur wisata Air Terjun Wiyono Atas sebesar 1,197. Nilai ini menunjukkan bahwa komunitas tumbuhan pada jalur kiri di jalur wisata Air Terjun Wiyono Atas termasuk dalam kategori keanekaragaman rendah. Berdasarkan data yang diperoleh, diketahui bahwa jumlah spesies tumbuhan penyusun vegetasi pada jalur kiri di jalur wisata Air Terjun Wiyono Atas adalah sebanyak 28 spesies tumbuhan dan memiliki 4 spesies dengan INP tertinggi. Sedangkan nilai indeks keanekaragaman pada komunitas tumbuhan di jalur kanan pada jalur wisata Air Terjun Wiyono Atas memiliki nilai sebesar 1,189. Nilai tersebut menunjukkan bahwa komunitas tumbuhan pada jalur kanan di jalur wisata Air Terjun Wiyono Atas termasuk pada kategori rendah. Berdasarkan data yang diperoleh, diketahui bahwa jumlah spesies tumbuhan penyusun vegetasi pada jalur kanan di jalur wisata Air Terjun Wiyono Atas adalah sebanyak 31 spesies tumbuhan.

Indeks Keanekaragaman digunakan untuk mengetahui tingkat keanekaragaman spesies tumbuhan pada semua fase pertumbuhan yang terdapat dalam suatu komunitas. Nilai $\mathrm{H}^{\prime}=<2$ tergolong rendah, nilai $\mathrm{H}^{\prime}=2-3$ tergolong sedang, dan $\mathrm{H}^{\prime}>3$ tergolong tinggi (melimpah). Nilai indeks keanekaragaman dipengaruhi oleh nilai INP dan jumlah seluruh spesies 
tumbuhan. Jika suatu spesies tumbuhan memiliki nilai INP yang tinggi, maka nilai keanekaragaman spesies tumbuhan juga tergolong tinggi.

Suatu komunitas dikatakan memiliki keanekaragaman spesies yang tinggi jika komunitas itu disusun oleh banyak spesies. Sebaliknya suatu komunitas dikatakan memiliki keanekaragaman spesies yang rendah jika komunitas itu disusun oleh sedikit spesies dan jika hanya ada sedikit saja spesies yang dominan (Indriyanto, 2008).

Penelitian lain yang telah dilakukan oleh Astuti (2009) menyebutkan bahwa indek keanekaragaman pada komunitas tumbuhan yang terdapat di sekitar jalur wisata Taman Wisata Alam Sicikeh-cikeh Kabupaten Dairi Sumatera Utara yang memiliki nilai indeks keanekaragaman sebesar 2,810 yang termasuk pada kategori keanekaragaman sedang. Dibandingkan dengan keanekaragaman pada jalur kiri dan jalur kanan pada jalur wisata Air Terjun Wiyono Atas Taman Hutan Raya Wan Abdul Rachman Provinsi Lampung yang memiliki keanekaragaman yang termasuk dalam kategori keanekaragaman rendah dengan nilai keanekaragaman sebesar 1,197 dan 1,819. Adanya perbedaan dari kategori keanekaragaman yang ada pada ke-2 tempat ini terjadi karena bentuk pengelolaan yang berbeda. Pada Air Terjun Wiyono Atas bentuk pengelolaan lahannya telah terjadi aktivitas penggarapan oleh masyarakat, sehingga menyebabkan kurang beranekaragam jenis tumbuhannya. Sedangkan pada jalur wisata Taman Wisata Alam Sicikeh-cikeh bentuk pengolaannya masih terproteksi sehingga berlangsung secara alami karena lokasi ini adalah Taman Wisata Alam terbatas.

\section{KESIMPULAN DAN SARAN}

\section{Kesimpulan} berikut.

Berdasarkan hasil penelitian yang telah dilakukan, diperoleh kesimpulan sebagai

1. 5 spesies tumbuhan dengan INP tertinggi di jalur wisata Air Terjun Wiyono Atas adalah spesies kakao (dengan nilai sebesar 66,45\%, kopi (Coffea arabica) dengan nilai sebesar 27,04\%, karet (Hevea brasiliensis) dengan nilai sebesar 25,72\%, cengkeh (Eugenia aromatica) dengan nilai sebesar $25,29 \%$, dan harendong bulu dengan nilai sebesar 15,48\%. Pada jalur wisata ini stratifikasi tajuk tergolong lengkap yaitu A, B, C, D, dan E.

2. Struktur vegetasi berdasarkan kerapatan tiap fase pertumbuhan membentuk kurva J terbalik yang berarti bahwa, regenerasi di jalur wisata ini berjalan cukup baik.

3. Keanekaragaman spesies tumbuhan pada jalur wisata Air Terjun Wiyono Atas tergolong rendah dengan nilai keanekaragaman $\left(\mathrm{H}^{\prime}\right)$ sebesar 1,189 pada jalur kanan dan 1,197 pada jalur kiri.

\section{Saran}

Sebaiknya pengelolaan dari Taman Hutan Raya Wan Abdul Rachman dapat menanami lebih banyak lagi jenis tumbuhan kayu rimba. Agar tetap dapat mewujudkan dari tujuan Tahura sebagai koleksi tumbuhan dan satwa yang akan dimanfaatkan bagi kepentingan penelitian, ilmu pengetahuan, pendidikan, menunjang budidaya, budidaya, pariwisata, dan rekreasi.

Jenis kayu rimba yang dapat ditanami harus disesuaikan dengan kondisi tempat tumbuh, kondisi klimatis, kondisi edafis, diutamakan jenis yang endemis suatu spesies, dan status langka berdasarkan kriteria yang ditetepkan oleh IUCN. Agar nantinya keanekaragaman jenis tumbuhan akan lebih bervariasi dan dapat tumbuh dengan baik. 


\section{DAFTAR PUSTAKA}

Astuti, S. S. 2009. Struktur dan komposisi vegetasi pohon dan pole di sekitar jalur wisata Taman Wisata Alam Sicikeh-Cikeh Kabupaten Dairi Sumatera Utara. Skripsi. Universitas Sumatera Utara. Medan. 112 p.

Dendang, B. dan W. Handayani. 2015. Struktur dan komposisi tegakan hutan di Taman Nasional Gunung Gede Pangrango Jawa Barat. Jurnal Kehutanan. 1(4) : 691-95.

Departemen Kehutanan Republik Indonesia, 1989. Kamus Kehutanan. Buku. Penerbit Departemen Kehutanan. Jakarta. 167 p.

Dwidjoseputro, D. 1994. Ekologi Manusia dengan Lingkungannya. Buku. Penerbit Erlangga. Jakarta. 133 p.

Harada, K., M. Rahayu, dan A. Muzakkir. 2006. Tumbuhan Obat Taman Nasional Gunung Halimun Jawa Barat Indonesia. Buku. Penerbit Palmedia Creative Pro. Bandung. $135 \mathrm{p}$.

Hidayat, S. 2015. Komposisi dan struktur tegakan penghasil kayu bahan bangunan di Hutan Lindung Tanjung Tiga Muara Enim Sumatera Selatan. Jurnal Manusia dan Lingkungan. 22(2) : 194-200.

Indriyanto. 2008. Ekologi Hutan. Buku. Penerbit Bumi Aksara. Jakarta. 210 p.

Meijaard, E., D. Sheil, R. Nasi, D. Augeri, B. Rosenbaum, D. Iskandar, T. Setyawati, M. Lammertink, I. Rachmatika, A. Wong, T. Soehartono, S. Stanley, T. Gunawan, dan T. O’Brien. 2006. Hutan Pasca Pemanenan Melindungi Satwa Liar dalam Kegiatan Hutan Produksi di Kalimantan. Buku. Penerbit Center For Internastional Forestry Research Bogor. 386 p.

Mirmanto, E. 2014. Komposisi foristik dan struktur hutan di Pulau Natuna Besar Kepulauan Natuna. Jurnal Biologi Indonesia. 10(2) : 201-211.

Odum, E. P. 1993. Dasar-dasar Ekologi. Buku. Penerjemah : T. Samingan. Gadjah Mada University Press. Yogyakarta. $679 \mathrm{p}$.

Oktora, N. 2013. Klasifikasi dan Morfologi Tanaman Kakao (Thebroma cacao). http:// www.petanihebat.com/. Diakses 05 Desember 2015 pukul 6.38 WIB.

Saipurrozi, M. 2010. Komposisi jenis tanaman yang di budidayakan petani di Areal Repong Damar Pekon Negeri Ratu Ngaras Kecamatan Bengkunat Kabupaten Lampung Barat. Skripsi. Universitas Lampung. Bandar Lampung. 54 p.

Satyowati, A. B., A. Sriyanto, A. W. Amsa, A. Santosa, A. Aliadi, B. Steni, C. Wulandari, E. Indraswati, F. Hanif, H. Alexander, I. Arsyad, N. Cahyoadi, S. Nurmawanti, W. Ramono, dan W. Suhmantoro. 2008. Konservasi Indonesia Sebuah Potret Pengelolaan dan Kebijakan. Buku. Penerbit Pesona Majapahit. Bogor. 78 p.

Simon, H . 1996. Metode Inventore Hutan. Buku. Penerbit Aditya Media. Yogyakarta. 586 p.

Simorangkir, R. H,. S.S. Mansjoer, dan M. Bismark. 2009. Struktur dan komposisi pohon di habitat orangutan liar (Pongo abelii) di Kawasan Hutan Batang Toru Provinsi Sumatera Utara. Jurnal Primatologi Indonesia. 6 (2) : 10-20.

Susanti, T., Suraida, dan H. Febriana. 2013. Keanekaragaman tumbuhan invansif di Kawasan Taman Hutan Kenali Kota Jambi. Prosiding Simarata FMIPA Universitas Lampung. 433-440.

Suwardi, A. B. 2013. Komposisi jenis dan cadangan karbon di hutan tropis dataran rendah Ulu Gandut Sumatera Barat. Jurnal Biologi. 12 (2) : 168-176.

Unit Pelaksana Teknis Daerah Taman Hutan Raya Wan Abdul Rachman. 2009. Buku Informasi Tahura. Buku. Unit Pelaksana Teknis Daerah Taman Hutan Raya Wan Abdul Rachman. Bandar Lampung. 38 p. 
Vol. 4 No.3, Juli 2016 (83-96)

Widiyanti, P. dan C. Kusmana. 2014. Komposisi jenis dan struktur vegetasi pada Kawasan Karst Gunung Cibodas Kecamatan Ciampea Kabupaten Bogor. Jurnal Silvikultur Tropika. 5 (2) : 69-79. 
Vol. 4 No.3, Juli 2016 (83-96)

Halaman ini sengaja dikosongkan 